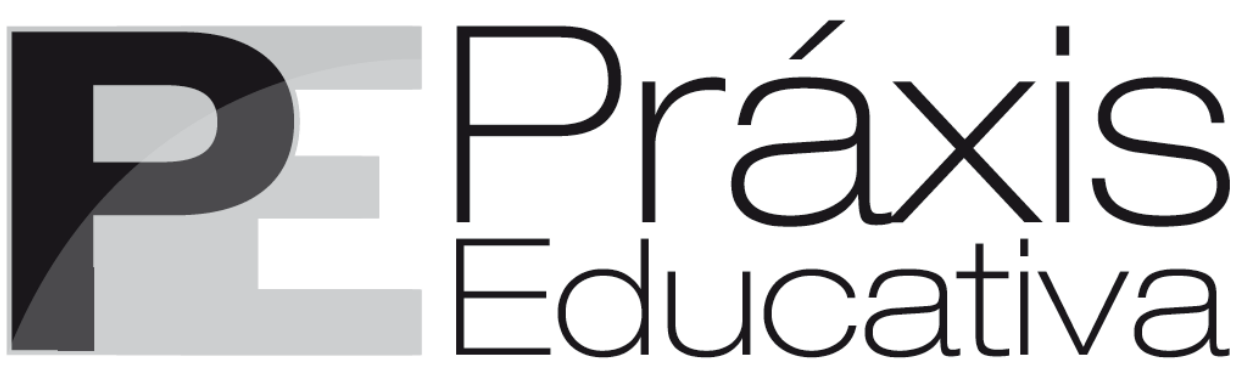

ISSN 1809-4309 (Versão online)

DOI: 10.5212/PraxEduc.v.11i3.0002

\title{
Políticas públicas: direito de aprender e avaliação formativa
}

\section{Public policies: right to learn and formative assessment}

\section{Políticas públicas: derecho a aprender y evaluación formativa}

Antonio Chizzotti*

\begin{abstract}
Resumo: Este artigo trata do direito de aprender no ensino de tipo escolar e considera a avaliação como garantia da qualidade do ensino e da aprendizagem. Ele trata dos processos avaliativos correntes e dos equívocos discriminatórios de avaliações meramente somativas, tendencialmente classificatórias dos alunos. Este texto avalia o viés punitivo das notações meritocráticas da aprendizagem e sustenta que somente a avaliação formativa pode garantir o direito de aprender.
\end{abstract}

Palavras-chave: Avaliação. Educação escolar. Avalição formativa. Direito de aprender.

Abstract: This paper deals with the right to learn in school type education and considers the assessment as assurance of teaching and learning quality. It deals with the current evaluation processes and discriminatory misconceptions of merely summative assessments, which tend to qualify students. This text evaluates the punitive bias of meritocratic grading of learning and argues that only formative assessment can ensure the right to learn.

Keywords: Assessment. School education. Formative assessment. Right to learn.

Resumen: El artículo trata del derecho de aprender en la educación en el entorno escolar y considera la evaluación como garantía de calidad de la enseñanza y del aprendizaje. Trata de los procesos de evaluación corrientes y conceptos erróneos discriminatorios de evaluaciones meramente acumulativa, que tienden a clasificar a los estudiantes. El texto evalúa el sesgo punitivo de notaciones meritocráticas de aprendizaje y argumenta que sólo la evaluación formativa puede garantizar el derecho a aprender.

Palabras clave: Evaluación. La educación escolar. Evaluatión formativa. El derecho a aprender.

\section{Educação: o direito de aprender}

A educação é a ciência que propõe ampliar o conhecimento humano por meio de processo de ensino e alcançar um resultado prático - o aprendizado. Pressupõe, de um lado, que o aprender é um desejo ínsito à natureza humana; é essencial para o desenvolvimento humano, para a realização pessoal, para a estabilidade social e para o desenvolvimento nacional; de outro lado, é possível de "[...] forma intencionada transmitir um acervo de informação, compreensão,

\footnotetext{
* Professor da Pontifícia Universidade Católica de São Paulo (PUC-SP). E-mail: <anchizo@uol.com.br>.
} 
conhecimentos, atitudes, valores, habilidades, competências e comportamentos de uma geração a outra" (UNESCO; ISCED, 2011). É, portanto, essencial para a manutenção e a reprodução da vida social.

Aprender é o componente central da educação e um direito básico universal, reconhecido, mundialmente, pela quase totalidade dos sistemas de educação; é um direito que torna possível outros direitos e contribui para a melhor participação e inserção social. O aprendizado pode derivar da experiência cotidiana, informal, não estruturada, que acontece no lar, nas interações informais com os membros da vida familiar - pais, irmãos ou parentes - ou no convívio com a comunidade circunstante. A qualidade de vida familiar e comunitária tem importância relevante na aprendizagem (FEYFANT, 2011; SCHNEIDER; KEESLER; MORLOCK, 2010), e muitos aprendem muito em contextos informais de ensino.

Aprender em uma instituição escolar, porém, é assumir uma proposta de aprender em um tipo de aprendizagem por meio de processos estruturados de ensino, com aplicação deliberada do aluno e com o auxílio de um professor, a fim de que o aluno eleve os conhecimentos adquiridos em outras instâncias e amplie as possibilidades do conhecimento humano. Pressupõe que tudo pode ser ensinado, e tudo que for bem ensinado pode ser aprendido, respeitadas as condições do aluno e do ensino.

A escola, para cumprir sua finalidade, organiza um percurso de aprendizagem, formalizado no currículo escolar com conteúdos, processos didáticos e aprendizagens esperadas com a finalidade de elevar o conhecimento do aluno, adquirido na vida cotidiana ou nas experiências da vida, e incluí-lo na vida e na cultura comuns da sociedade.

O Estado, no exercício de sua jurisdição, precisa, para sua sobrevivência e seu desenvolvimento, que todos os cidadãos aprendam em um sistema estruturado de ensino, ao menos os conhecimentos básicos para participar da vida social e cultural do país e, depois, possam alcançar outros níveis de aprendizado, durante toda a vida, por meio de múltiplos processos de ensino. Todo estado moderno organiza o respectivo sistema de educação para atender ao direito à educação para todos e garantir sua sobrevivência social e política.

O direito à educação não se limita ao acesso à escolaridade, garantido pelo Estado, condição elementar do direito de aprender; a finalidade da escola é garantir o direito de todo cidadão aprender, em um contexto estruturado e formal de ensino. Aprender é componente central do sistema de ensino e é obrigação objetiva do estado democrático prestá-la aos seus cidadãos. $\mathrm{O}$ acesso à escola, reconhecido oficialmente por todos os estados civilizados, é mero pressuposto inderrogável do direito de aprender, embora o relatório da Educação Para Todos de 2012 (UNESCO; UNICEF, 2012) revele que, ainda, 250 milhões de crianças em idade escolar no mundo não sabem suficientemente ler, escrever e contar para atender os elementos mínimos de aprendizagem, inclusive aquelas que passaram ao menos quatro anos nas escolas.

O relatório mundial sobre as crianças não escolarizadas, publicado pela UNESCO e UNICEF (2015), para avaliar o resultado do Programa Mundial da Educação para Todos, em favor das crianças não escolarizadas, atesta que 121 milhões de crianças e adolescentes nem começaram ou abandonaram a escola, apesar da promessa de educação primária universal até 2015. Além disso, não houve progresso na redução no número de crianças que trabalham ou são vítimas de discriminação por causa da etnia, sexo ou carência social. Segundo o Relatório, um em cada cinco adolescentes está excluído da escola; uma em cada onze crianças em idade escolar corre o risco de ser excluída e, na medida em que elas crescem, aumenta o risco de exclusão. O prêmio Nobel da Paz 2014, concedido à jovem paquistanesa Malala Yousafzai, de 17 anos, sobrevivente de atentado à bala na cabeça por membros do Talibã paquistanês por defender a

Práxis Educativa, Ponta Grossa, p. 561-576, v. 11, n. 3, set./dez. 2016 Disponível em: < http://www.revistas2.uepg.br/index.php/praxiseducativa > 
educação escolar das mulheres em seu país, é um atestado da distância entre o reconhecimento universal de um direito e a subsistência de bolsões bárbaros de odiosa discriminação ao aprendizado escolar contra parcelas da sociedade, por causa do sexo, da origem social, da raça ou de outras absurdas discriminações subsistentes.

O episódio atualiza a questão basilar que muitos educadores se põem sobre os objetivos da escolaridade pretendida pelo Estado, pelos professores, pelas famílias e pelos alunos no mundo contemporâneo globalizado. As proclamações oficiais de todos os sistemas de educação declaram que objetivam oferecer a possibilidade de todo cidadão adquirir os conhecimentos e as competências indispensáveis à sua integração social e prepará-lo para desempenhar alguma função especializada na sociedade. Essa dupla finalidade depende muito da história e dos objetivos específicos, políticos, econômicos e culturais de cada país: a acumulação competitiva e concorrencial de conhecimentos, como na Coreia do Sul e outros países, ou a igualdade, o desenvolvimento pessoal e social, como na Finlândia e outros sistemas de ensino. Essas finalidades específicas, implícitas ou explícitas da escolaridade, determinam muito o tipo de avaliação que se quer praticada no ensino escolar.

\section{Avaliação: alavanca ou guilhotina do aprendizado}

$\mathrm{Na}$ escola e nos processos formais de educação, parte-se do princípio que é possível aprender por meio do ensino. Ensinar é algo externo ao aluno e supõe que alguém, com experiência e competência, pode promover novos conhecimentos ao aprendiz. Aprender é o resultado esperado do processo de ensino. Há um vínculo indissociável entre aprender e ensinar na educação escolar; o resultado desse processo é atestado pela avaliação, consequência indeclinável do processo educativo.

A avaliação é inerente a todo processo educativo: visa garantir a apropriação do saber transmitido, reconstruído ou recriado e, como tal, é um processo avaliativo de encantamento com o que pode ser aprendido na relação com quem ensina. A avaliação é um meio histórico de qualificar a educação. $\mathrm{O}$ direito de aprender pode e deve, pois, ser avaliado para assegurar a qualidade da aprendizagem e o sucesso do ensino. Ela visa, essencialmente, garantir o direito inalienável de aprender.

Nada mais avilta a educação, porém, que aprender ou ensinar sob o jugo de qualquer forma, explícita ou velada, de opressão. Como um histórico educador, Santo Agostinho (2000, p. 14) ensina, nos primeiros séculos do primeiro milênio, que "[...] para aprender é mais eficaz uma curiosidade espontânea do que um constrangimento ameaçador", ou, como conclui todo pesquisador atento: nada é mais vil e distante da educação do que precisar aprender sob o peso do medo servil de um castigo. O pressuposto da avaliação educacional é que se pode aquilatar o resultado da aprendizagem e qualificar o sucesso do ensino, e somente tem sentido educacional se constituir uma alavanca para o aprendizado, não a guilhotina. Alunos e professores sabem do poder terrível da avaliação: pode abrir as sendas de um horizonte virtuoso para aprender, criar, inventar ou provocar um desastre existencial na interação educacional, que se estende pela vida. A avaliação tem uma relação indissociável com todas as atividades educativas desde a elaboração dos currículos, as práticas didáticas e as escolhas dos conteúdos que deverão ser mobilizados para a formação pretendida pela educação escolar. É, pois, substantiva a todo projeto educacional. 


\section{Aprender e os processos avaliativos}

Em educação, a avaliação abrange diferentes processos com âmbitos e finalidades específicas sobre os sistemas, as organizações, as instituições e os programas de ensino, em inglês, designado como evaluation, distinto de assessment, que designa a avaliação do desempenho de aluno. Em português, não há essa distinção. Este estudo analisa alguns aspectos da avaliação para a aprendizagem progressiva do desempenho do aluno no ensino de tipo escolar (assessment), prevista pelo sistema de educação oficial.

A tipologia das avaliações de alunos pode pretender, com recurso a um conjunto de procedimentos, obter informação do desenvolvimento de um programa ou de um aluno (diagnóstica), aferir o nível alcançado por uma população escolar (prognóstica) contar os saberes adquiridos (somativa), atestar um nível de ensino alcançado (certificativa) ou favorecer a progressão criativa do conhecimento do aluno por meio de apoios contínuos, que despertem as potencialidades do aluno e animem a criatividade formadora do professor. Em qualquer tipologia, a avaliação fundamenta-se em um "[...] juízo de valor e sempre evoca concepções teóricas sobre a avaliação, os pressupostos em que ela se fundamenta, os critérios adotados, as finalidades perseguidas, os resultados alcançados e os usos da avaliação" (CHIZZOTTI; PONCE, 2010, p. 3).

As avaliações tornaram-se extremamente relevantes nas políticas comparativas entre sistemas de ensino e a avaliação do resultado da aprendizagem do aluno, a partir do Programa Internacional de Avaliação de Estudantes, conhecido pelo acrônimo inglês PISA (Programme for International Student Assessment). Este se tornou a referência basilar na hierarquização das instituições e sistemas de educação internacional ao definir um padrão esperado de qualidade e eficiência, e estabelecer aproximações comparativas entre sistemas nacionais ou estabelecimentos de ensino. Os processos de avaliação dos sistemas de ensino, tal como o PISA e similares, avaliam os professores, os estabelecimentos educativos e os sucessos pedagógicos escolares, tendo como referência os resultados obtidos pelos alunos. Servem para os professores e para os estabelecimentos escolares criarem posições comparativas com outros estabelecimentos. Não avaliam os alunos, nem são adequadas para verificarem as avaliações da ou para a aprendizagem dos alunos. O viés competitivo dessas avaliações comparativas de sistema, se introduzido nas avaliações para a aprendizagem, conturba o processo educativo e provoca tensa ambiguidade nas avaliações cotidianas nas escolas e equivocada uniformização nos processos avaliativos do desempenho do aluno.

As avaliações escolares certificativas confirmam oficialmente a conclusão exitosa de um nível ou programa de ensino, atestando as aprendizagens requeridas para um determinado ciclo de estudos, por meio de um diploma ou credencial. A maioria dos sistemas de ensino valida um nível de escolaridade por um certificado de conclusão. A avaliação certificativa, exclusiva até a metade do século passado, passou a ser considerada, a partir da década 1960, segundo Scallon (2007), como um processo somativo de verificação contínua da aprendizagem.

\section{Aprender e a avaliação somativa}

As avaliações mais diretamente visíveis no discurso escolar, e fonte de debates políticos, são as avaliações somativas: servem para medir o que os alunos aprenderam ao fim de uma unidade de ensino, para aprovar o aluno ao final do ano escolar, para atestar o nível exigido para obter um diploma e prosseguir nos estudos. Os Ministérios de Educação utilizam a avaliação somativa para analisar a pretendida qualidade do ensino que os estabelecimentos públicos dispensam aos alunos, e os programas derivados do PISA usam as avaliações somativas para

Práxis Educativa, Ponta Grossa, p. 561-576, v. 11, n. 3, set./dez. 2016 Disponível em: <http://www.revistas2.uepg.br/index.php/praxiseducativa> 
comparar ou ranquear sistemas de educação internacionais. Nos últimos decênios, nos países da Organização para a Cooperação e Desenvolvimento Econômico (OCDE), a atividade pedagógica dos professores foi, progressiva e obrigatoriamente regulamentada, sob a forma de programas escolares formulados em termos de objetivos pedagógicos ou em standards, como o National Curriculum, na Inglaterra, ou o socle commun, na França (CENESCO, 2014). No Brasil, depois de propor parâmetros e diretrizes, a Secretaria da Educação Básica, em 2015, propõe a discussão sobre a construção da base nacional comum curricular (BRASIL, 2015). Se a avaliação certificativa apoiada na avaliação somativa foi o modelo avaliativo dominante até o último quartel do século passado, novas teorias relevaram suas limitações e fragilidades, e a importância da avaliação formativa para elevar a qualidade da educação escolar. A avaliação para aprender supõe, necessariamente, a avaliação formativa, feita pelas "[...] avaliações frequentes dos progressos e dos resultados dos alunos a fim de identificar as diversas necessidades dos alunos para diferenciar e ajustar, adequadamente, o ensino a fim de melhorar os níveis dos alunos e a equidade dos resultados" (OCDE; CERI, 2008). Só tem sentido, segundo Nusche et al. (2013), a avaliação que tenha um valor educativo coerente e alinhado com os objetivos claramente compreendidos pelos atores da educação e favoreça aprendizagens ulteriores, ou se for utilizada para reprogramar o ensino. A atualidade e oportunidade, pois, da avaliação formativa merece um estudo particular. Ela, porém, porfia com a prática disseminada das avaliações somativas e a credulidade generalizada de que a somatória de pontos positivos pode representar um sucesso quantificado e objetivo de aprendizagem, expresso em documentos oficiais de escolaridade, boletins e atestados curriculares.

Para alguns, as avaliações somativas parecem ser, sob algumas condições, compatíveis com as avaliações formativas (OCDE; CERI, 2008); para outros, há uma radicalidade inconciliável entre processos formativos e somatórios de acertos (MAULINI, 2012), mas é ilusório que métodos de avaliação de sistemas aptos para estabelecer relações comparativas entre estabelecimentos ou sistemas escolares possam ser utilizados pelos professores para avaliar o aprendizado dos alunos nas avaliações cotidianas em sala de aula. A adoção e a generalização de indicadores comparativos de resultados induzem a uma ditadura de indicador, à política de números e à burocratização do controle com a consequente saturação das atividades pedagógicas do professor por cumprimentos formais, que absorvem sua atenção e tempo, em prejuízo da atenção aos alunos.

As avaliações somativas são herdeiras de uma longa tradição dicotômica e de um processo contínuo e inseparável entre ensinar e aprender, e entre docente e discente. Essa separação tributa infalibilidade ao ensino, e a avaliação torna-se uma intervenção a posteriori do processo de ensino, obrigatoriamente exigível por meio dos acertos mensuráveis do aluno. Gera, na prática docente, uma convicção de que a somatória dos acertos dos alunos representa sucesso do ensino; e os erros, a incompetência discente para aprender.

Essa dicotomia cria uma contradição insanável na educação: o desejo de aprender pode ser substituído pela obrigatoriedade coativa do aprendizado, uma ameaça persistente (BUTERA; BUCHS; DARNON, 2011), ou seja, a punição, radicalmente contrária a todo processo educativo, passa a ser admitida como meio para garantir o aprendizado. Ora, nada mais compromete a educação que obrigar alguém ao ensino, sob o tacão material ou simbólico da punição. Esse equívoco gerou, historicamente, uma tradição de que educar e punir é parte integrante de um mesmo processo. Se história da avaliação comporta uma variedade de modalidades (CARDINET, 1991; RYAN; COUSINS, 2009), a avaliação individual do aprendizado sempre esteve conexa às concepções penais de cada período, e as práticas avaliativas dos sistemas de ensino dependeram da estrutura econômica e social de cada época e das formas coercitivas de vigiar e punir (FOUCAULT, 2009).

Práxis Educativa, Ponta Grossa, p. 561-576, v. 11, n. 3, set./dez. 2016 Disponível em: < http://www.revistas2.uepg.br/index.php/praxiseducativa> 


\section{Avaliar versus punir}

$\mathrm{Na}$ educação escolar, a função punitiva da avaliação pode ser sintetizada em quatro modalidades históricas, segundo Prairat (1994): punições expiatórias na e pela dor corporal, como meio da purificação penitente para sanar o erro; punição-sinal, uma caracterização ostensiva, desonrosa ou infamante, para sinalizar a incompetência, tal como a orelha de burro, nota de fracasso ou reprovação; punição-exercício, a execução mecânica de um texto repetitivo de duração tediosa para o punido adestrar-se na repetição formal de uma tarefa corrigida; ou, ainda, a punição, o banimento, a exclusão física do aluno seja da sala ou da escola, quando não se pode controlar a disciplina intelectual ou comportamental. O viés coativo, motivo de temor ameaçador permanente na trajetória escolar do aluno, paira difusamente presente nas práticas avaliativas, confirmando o poder pedagógico docente e, segundo Merle (2012), é o signo segregativo do ensino: uns ostensivamente predestinados para o sucesso e outros publicamente assinalados para o fracasso. A reprovação decreta o fracasso. A despeito das pesquisas, pouco conhecidas, mostrarem a ineficácia da reprovação (HEIM; TRICOT; STEINMETZ, 2015), questão clássica do discordo entre pesquisas e docentes nessa questão, as pesquisas não têm modificado essa crença apoiada no suposto de que a reprovação é um sinal necessário para exigir do aluno um tempo de maturação, um nível de exigência que ele deve perseguir para mobilizá-lo para o sucesso; e, no nível institucional, mostrar o alto nível de exigência da escola, reduzir a heterogeneidade das classes, confortar a autoridade dos professores e estabelecer um diálogo justificado com as famílias (CNESCO; IFÉ, 2015).

A sanção foi progressivamente, no século XIX, suplantada pela gratificação e as penas substituídas pelas recompensas, segundo Prairat (2009), e os professores aconselhados a recompensar mais que castigar e, assim, incitar o desejo dos preguiçosos a também serem recompensados como diligentes, antes que pelo temor do castigo. Foucault (2009) mostra como as marcas visíveis de louvor ou infâmia, similar às distinções honoríficas dos quarteis, torna-se uma arte que visa normalizar antes que reprimir. Assim, no século XIX, os castigos corporais foram substituídos por motivações extrínsecas: recompensas antes que punições, honrarias mais que desonras, por meio de um balanço quantificado de classificação com a adoção de um modelo de precisão aparente - a nota decimal - e, por meio dela, a classificação hierárquica entre os bons e maus, apoiado no veredito público da notação escolar (BURGNARD, 2004). No século XIX, a aspiração da burguesia à educação escolar, apoiada no princípio da emulação da Ratio studiorum, vai contribuir para uma nova ordem escolar: a meritocracia e a política seletiva meritocrática de seleção social, segundo o lema "a cada um conforme seu mérito", como norma classificatória do sucesso escolar. O mérito garante a distribuição desigual entre os alunos, acreditando que há uma superioridade natural de uma aristocracia do espírito; essa naturalidade sustenta a reprodução necessariamente elitista dos detentores dos recursos materiais e simbólicos do conhecimento. A passagem para uma educação estatal de massa de um Estado, como promotor da educação, pressupôs a disponibilização de meios para controlar os comportamentos, disciplinar os corpos, classificar os melhores para estabelecer a hierarquia entre alunos, classes e instituições, e selecionar uma elite, por meio da notação de cada coorte de alunos (MAULINI, 1996). Apesar da pesquisa lacunar sobre a adoção dos pontos e números, que fundamenta a avaliação somativa, a discriminação dos melhores e a identificação dos piores por indicadores numéricos de sucesso e fracasso permitiu expandir um sistema meritocrático, que consagrou a reprodução social das desigualdades e fez a triagem dos melhores, mantendo, no analfabetismo, a pobreza intergeracional- tal pai pobre, tal filho necessariamente pobre - oferecendo a educação primária às camadas populares, a educação média aos níveis intermediários e a educação superior às elites.

A despeito das transformações dos conteúdos escolares e dos avanços teóricos do campo da avaliação escolar, ela permanece, dominantemente, tradicional, somativa, concentrada no 
número delimitado de resultados cognitivos que possa ser referência para notação. A nota, derivada de notus - conhecido do verbo latino noscere - conhecer, ingressa na educação como caracterização do resultado do ensino, presente na grande maioria dos sistemas de educação. Ela está no centro de debate político como padrão definidor da identidade qualificada do aluno, apesar de todas as interrogações que a medida numérica da aprendizagem levanta e de clamores contra a função segregativa dessas avaliações, que beneficia, como melhores, aqueles que têm melhores condições de aprendizagem e estigmatiza os que mais precisam de apoio e reorientação de suas atividades na educação escolar (MERLE, 2007, 2012).

O pressuposto epistemológico da pontuação do mérito valida um projeto sócio político: para os sistemas centralizados de educação, frente ao desenvolvimento da educação massiva, a classificação assume um papel de controle social do público escolar: eleger elites e segregar os futuros trabalhadores (HADJI, 2012). A reprovação é a epígrafe dos vencidos. Há, reconhece a literatura francesa (LHÉRETÉ, 2014), um confronto entre o pedagogo, tendo o educando como centro, sua curiosidade, sua inteligência e seu desenvolvimento, e os republicanos privilegiando o mérito, a disciplina, o esforço e a autoridade do professor.

\section{O fetichismo da notação do aprendizado}

A nota é o epígono desse projeto epistemológico e sociopolítico, amplamente acreditado e professado nos rituais de certificação do conhecimento escolar e produto de um sistema de educação centralizado, organizado em níveis e graus sucessivos, por meio de exames certificadores de cada etapa, completando com a classificação final dos bem-sucedidos e declaração oficial dos excluídos.

A notação responde, pois, a um projeto epistemológico do conhecimento: crê que o conhecimento possa ser redutível à formalidade matemática, obedecendo ao rigor objetivo da medida: a docimologia de Piéron, a psicometria de Binet ou a edumetria de Landsheere aprimorou a busca de um critério mensurável de rigor para dar suporte a um projeto sociopolítico: a exatidão da medida parece assegurar a igualdade de chance e acredita viabilizar a distribuição equânime de oportunidades de um projeto meritocrático, e , assim, recompensar cada um segundo seus méritos. Embora esse tipo de metrificação tenha entrado em desuso, floresce um movimento de avaliação empírica por meio de análises estatísticas sofisticadas da avaliação de sistema, apoiadas nos resultados do PISA e, por adoção, transladadas para a performance do aluno em classe, como propugna, por exemplo, a Society for School Effectiveness Research e movimentos congêneres (CHIZZOTTI, 2015; TEDDIE; REYNOLDS, 2000) ou adotado como padrão único de pesquisa científica pelo Comitê Científico do Conselho Nacional de Pesquisa dos Estados Unidos (NATIONAL RESEARCH COUNCIL, 2002, 2005).

As políticas públicas tendem a regulamentar a prática avaliativa, no plano cognitivo, para adquirir maior conhecimento; no plano normativo, para fundamentar juízo e tomar decisões; no plano instrumental, para propor melhorias. Um estudo_comparativo internacional nos países da OCDE mostra que as políticas educacionais de cada país regulamentam que as convenções de mensuração da avaliação sejam pela supressão de notação, como na educação primária na Finlândia, na Suécia e na Dinamarca, substituídas por balanços qualitativos. Em outros países, a notação é substituída por letras, A, C e E, tal como na Suécia; e, em outros, os algarismos exprimem valores diferentes: na Alemanha, no primário e no colégio, a escala é de 1 (muito bom) a 6 (insuficiente); no gynasyum, de 0 a 15; no profissional de 1 a 6. Na Coreia do Sul e Quebec, de 0 a 100, na Dinamarca de -2 a 12 (CNESCO, 2014).

Práxis Educativa, Ponta Grossa, p. 561-576, v. 11, n. 3, set./dez. 2016 Disponível em: < http://www.revistas2.uepg.br/index.php/praxiseducativa > 
A nota é uma convenção precária para ajuizar uma apreciação. Mais que uma medida objetiva, um "termômetro" do aprendizado do aluno, a avaliação é sempre um juízo de valor e, por mais que se ampare em suportes quantificados, está impregnada da inevitável subjetividade e preferência do professor, que malgrado toda boa vontade, a medida avaliativa é influenciada por múltiplos vieses sobre o aluno: origem social, sexo, aparência pessoal, histórico escolar, reprovação antecedente, entre outros como mostram Castincaud e Zakhartchouk (2014). Merle (2007, 2014) estudou o processo de "fabricação" das notas no ensino secundário francês, e a mostrou resultante de uma bricolagem de muitos elementos e situações que são introduzidas para compor a notação.

A fixação de um chão ou um teto e a diferença entre notas três e nove mostram considerável discrepância, mas diferenças pequenas entre quatro e cinco são muito arbitrárias e, se expostas a múltiplas correções, levam a resultados bem diferentes (SUCHAUT, 2008). Nem se pode garantir, também, que a nota ou média de notas de um semestre ou de um ano ateste o nível de conhecimento ou competência do aluno.

Professores estão, em geral, convencidos do valor e da fiabilidade da nota. Ela é questão sensível ao docente, pois trata-se de um instrumento essencial para assegurar sua autoridade ou popularidade pedagógica, garantir a disciplina em classe e gratificar ou reprovar o comportamento dos alunos, certificar a progressão nos estudos e validar, publicamente, o aprendizado. Eles acreditam, também, que a nota provoca uma emulação sadia entre os alunos e serve como poderoso estímulo ao aprendizado, pois os professores afirmam que os próprios alunos sempre desejam saber se a atividade "vale para nota?", e, se afirmativo, empenham-se para alcançar boas notas. Desse modo, os docentes tendem a cultivar a rivalidade entre alunos, estimular a competição entre eles e exigir de todos os alunos a conformidade obediente aos cânones disciplinares uniformes, por meio de promessas de acréscimo ou rebaixamento da nota.

$\mathrm{Na}$ verdade, a nota classificatória pública compromete a educação. A recompensa da nota, como uma motivação externa ao sujeito-aluno, desqualifica outras motivações intrínsecas, como o desejo, a curiosidade, o interesse em aprender. Os que estão empenhados na competição surda pelo sucesso montam suas estratégias para atender aos conteúdos previstos pela avaliação quantificada, a fim de obter melhor classificação, orientam seus esforços para atender os exames previstos ou exames finais, ajustam sua aplicação aos conteúdos passíveis de notação e, assim, ostentar seu sucesso, em prejuízo de outras aprendizagens relevantes. Aqueles conhecimentos que não compuseram a notação e todos aqueles conhecimentos meramente memorizados para acrescer a notação logo são esquecidos. Sem a motivação interna, a instrumentalização do aprendizado esgota-se com a obtenção da nota. A avaliação como sinônimo de medida e sua função classificatória, seletiva e excludente é objeto de crítica aberta na Carta de Campinas do Seminário de Avaliação e Políticas Públicas Educacionais, ocorrido em 2011 (CEDES, 2011).

O clima competitivo mina o processo educacional ao classificar alunos com boas ou más notas, pois exalta os bem-sucedidos que, por muitos meios, têm o domínio da cultura escolar e obtêm os primeiros lugares. Além disso, cria, nos alunos com más notas, uma imagem negativa de si mesmos, que os desencoraja de aprender com os outros. Esse clima arruína o convívio solidário e cooperativo, e os que tiverem baixa classificação ficarão expostos à depreciação coletiva, ao temor do fracasso e, cada vez mais, abominarão o convívio escolar.

Quando o aluno considera que a nota não recompensa seu esforço de modo justo, ele perde a motivação, e a relação pedagógica fica comprometida, irremediavelmente, pois o aluno identifica muitos ingredientes ocultos de avaliação que considera injusta: sua condição social, seu histórico, o estereótipo que fazem dele. A notação refina e reinventa, na escola moderna, a noção punitiva da avaliação por meio do estigma das notas más; seleciona e exalta como melhores os 
que alcançarem boas notas e marginaliza e humilha os que tiverem as piores notas; enfim, discrimina aqueles que maior necessidade têm da escola e de um aprendizado feliz, em benefício dos mais favorecidos e que menos necessidade têm da instituição escolar. Em suma: dá mais aos que mais têm; e pouco aos que menos têm. Maulini (1996) faz uma proclamação vigorosa contra a pontuação na avaliação:

Suprima-se a nota! Vamos abolir esses grilhões que mantiveram gerações no cativeiro. Renunciemos a avalição quantificada, os cálculos complicados das médias, os impasses da seleção aritmética. Então virá a aurora de uma pedagogia reconciliada consigo mesma, sem cenoura nem vara. Um novo porvir nascerá para as classes, sem as notas, sem a concorrência nefasta, nem a hierarquia nauseabunda: os alunos serão mais solidários, os professores mais serenos, os pais melhor informados. O saber encontrará o seu significado, o ensino será, para isso, diferenciado, a aprendizagem facilitada e o fracasso escolar erradicado. (MAULINI, 1996, p. 1).

O autor invoca a denúncia de Claparède (1920), no século passado:

A escola atual quer sempre hierarquizar [...] essa ideia fixa de hierarquia provém dos diversos sistemas para incitar os alunos: boas ou más notas, classificações, punições, concursos, prêmios [...] no futuro todos esses expedientes não terão mais importância. O interesse será a grande alavanca que dispensará todos os outros. (CLAPARÈDE, 1920 , p. 30).

\section{Equívoco da notação}

O equívoco presente na notação educacional é avaliar o resultado da aprendizagem desconexo do processo do ensino. Avaliar quem aprende, ex post, sem avaliar, ex ante, a qualidade e a propriedade do ensino cria um processo falacioso de avaliação que permite creditar o insucesso do aprendizado, quando ocorre, somente ao aluno. Em termos elementares, divide parte de um processo que forma um contínuo unitário e tributa o sucesso ou o insucesso da aprendizagem a um dos atores, ocultando, nesse processo, o outro interlocutor responsável pelo ensino. $\mathrm{O}$ fetichismo da notação pode, desse modo, aparentar, equivocadamente, um processo criterioso, isento de contaminações subjetivas, com um resultado mensurável objetivo do aluno, traduzível em pontos da notação. Antibi (2003), um professor de matemática e pesquisador na área da educação, denuncia a constância macabra das notas, principalmente em matemática e língua nacional que, para serem críveis, precisariam seguir a curva de Gauss: dividir os alunos de uma classe em um terço de bons, um terço de médios e um terço de maus, acreditando mais no fracasso do que no sucesso, apoiado na hipótese de que não se tem somente bons alunos em classe e é de bom tom dar más notas. O autor e o Movimento Contra a Constante Macabra (MCLCM), liderado por Antibi, propõem uma Avaliação por Contrato de Confiança (EPCC Évaluation Par Contrat de Confiance) entre aluno e professor (1).

Outro argumento em favor da nota apoia-se nas exigências das famílias para saber dos progressos de seus filhos e cobram as notas de aproveitamento. Há exemplos de tentativas de eliminação das notas para definir aprovação ou reprovação, que tiveram de ser revertidas em razão da pressão docente, secundada pela demanda das famílias. O que os pais querem é acompanhar a esperançosa oportunidade que a escola pode oferecer na formação de seus filhos. São temerosos das dificuldades que os filhos possam encontrar no regime escolar, confiam na compreensão dos professores ou nas amizades do convívio escolar para auxiliar nessa formação, e, como maiores interessados no sucesso dos filhos, esperam que a escola ofereça as indicações dos progressos de seus filhos. Se a nota for o único meio de avaliação da escola, os pais apoiarse-ão nessa referência: as famílias com filhos bem-sucedidos ficarão confortadas e farão maior exigência da notação, como prognóstico do sucesso dos filhos; as famílias ou contextos familiares

Práxis Educativa, Ponta Grossa, p. 561-576, v. 11, n. 3, set./dez. 2016 Disponível em: < http://www.revistas2.uepg.br/index.php/praxiseducativa > 
mais vulneráveis acompanharão, com a mesma ansiedade do aluno, a previsão do insucesso anunciado das notações.

\section{Avaliação formativa}

A avaliação para aprender supõe uma nova concepção do processo do ensino e da aprendizagem, uma avaliação que não se reduza à quantificação de resultados mensurados de respostas esperadas do conteúdo ministrado, mas que incorpore os grandes avanços científicos nesse campo especializado do conhecimento, instaure uma nova cultura avaliativa para a aprendizagem e, segundo Barreira, Boavida e Araújo (2006), mostre a função insubstituível dessa modalidade de avaliação na formação dos professores e a necessidade de pô-la em prática para conscientizar os alunos de suas potencialidades. Ela deve despertar o sentimento de capacidade e de autonomia pessoal do aluno; incentivar a motivação pessoal de cada um; favorecer o gosto pelo aprendizado no contexto escolar, junto a docentes atentos e colegas colaborativos; e, por outro lado, abdicar de qualquer viés coativo na apreciação das atividades discentes; abandonar a classificação entre melhores e piores e qualquer laivo de ranqueamento entre bons e maus; tornar-se, enfim, fundamento de um processo emancipatório dos alunos.

Consonante com a avaliação formativa, Saul (1995) propõe o paradigma da avaliação emancipatória com o objetivo de iluminar o caminho da transformação e beneficiar as audiências no sentido de torná-las autodeterminadas. O problema nuclear não está na mera supressão da nota, mas em uma cultura de avaliação que dá credibilidade objetiva à notação e autoriza o uso arbitrário e público de classificação, segregação e discriminação entre bons e maus, caracterizados pela nota.

A avaliação formativa, termo introduzido na década de 1970 (BLOOM; HASTING; MADAUS, 1983) sugeria que a avaliação formativa poderia ter influência mais positiva para a aprendizagem do aluno do que avaliações meramente somativas do desempenho dos alunos. Em alguns contextos escolares atuais com muitas precariedades patentes, a avaliação formativa pode soar como um hilário e trágico "sonho numa noite de verão" shakespeariano - quanto muito poderão aceitar como complementar à notação tradicional. Contudo, a ampla pesquisa de Black e Wiliam (1998) na literatura anglófona sobre as práticas da avaliação formativa na Educação Básica em leitura, escrita, estudos sociais, matemática e ciências revelou as vantagens da avaliação formativa, mudou o panorama da avaliação e foi responsável pela difusão de uma nova compreensão da avaliação, pois ela melhora efetivamente a aprendizagem, pode reduzir as desigualdades e contribuir para maior nível de equidade. O que emerge da literatura estudada é o conjunto de princípios norteadores com a admoestação, "[...] as mudanças na prática em sala de aula são necessárias, centrais e não marginais; devem ser incorporadas por cada professor em sua prática e em seu próprio modo de ser" (BLACK; WILIAM, 1998, p. 61). Avaliação, para garantir o direito de aprender, só tem sentido se for contributiva ao processo de aprendizado do aluno.

A avaliação formativa confronta-se com muitos obstáculos: primeiro, com a prática generalizada da avaliação, somente somativa, e a confiança dos professores na objetividade e na neutralidade da atribuição de notas aos seus alunos; segundo, com a demanda dos pais que desejam ter uma referência para o andamento escolar de seus filhos e só conhecem a notação como método de avaliação. Por outro lado, as escolas, sempre pressionadas pela apresentação de resultados quantificados da aprendizagem dos alunos, requerida pelas instâncias administrativas, ou por elas próprias, desejosas de alcançar evidência e visibilidade nas avaliações do sistema de ensino, mostram-se inseguras e refratárias à transformação radical da tradição somativa de avaliação. 
A avaliação é um campo de conhecimento especializado, mas os professores, apesar de ser questão central de sua atividade docente, têm uma formação muito precária nesse campo e aderem às avaliações somativas como único meio que conhecem de certificar o aprendizado dos alunos e, pressionados pelas avaliações externas, estruturam-se para alcançar melhor resultado nas classificações competitivas dos sistemas de ensino. A proposta da Conferência Internacional da OCDE (OCDE; CERI, 2008), Aprender no século XXI, considera que os princípios da avaliação formativa podem ser aplicados no nível dos estabelecimentos e das políticas para "[...] determinar os domínios que devem ser melhorados e promover uma cultura eficaz e construtiva da avaliação em todos os níveis do sistema educativo" (OCDE; CERI, 2008, p. 1). Ela incorpora as sugestões de Black e Wiliam e converge na indicação de algumas vias indicativas, conforme Crahay (2007) e Rey e Feyfant (2014). Supõe uma nova cultura de avaliação que abranja a escola, o professor e o aluno, com o objetivo central de auxiliar, de forma proativa, o aluno a construir progressivamente sua aprendizagem. Parte das necessidades de uma planificação que defina os objetivos pedagógicos, os critérios de avaliação formativa e explicite os meios de alcançá-los. Esforços disciplinares isolados, iniciativas sem objetivos claros, atendimento às outras exigências externas, administrativas comparativas ou classificatórias de unidades ou sistemas escolares comprometem o propósito formativo da avaliação do aluno em classe. A avaliação que forma se apoia no contínuo reforço da motivação do aluno e no incentivo à sua capacidade de ampliar sua competência em aprender, e ele próprio saber autoavaliar seu desempenho, suas necessidades e seu próprio sucesso ou carências.

Cabe ao professor auxiliar nesse processo, atento aos variados modos de ensinar adaptados às necessidades dos alunos e recorrer a métodos diversos de reconhecer o resultado obtido pelo aluno e as múltiplas formas de seu sucesso. A formação científica do professor em avaliação é, porém, reconhecidamente, precária e elementar nos cursos de formação docente, diante dos debates e avanços internacionais desse campo de atuação de educadores. O professor deve ser, necessariamente, um especialista em avaliação, apto para reconhecer sua responsabilidade profissional e ética de dominar as práticas e técnicas de avaliação, imprescindíveis ao seu ofício, reunir informações compreensivas de aluno e formular uma orientação favorável ao sucesso de seu aprendizado e uma atuação contínua e positiva para o aluno superar os obstáculos por meio de incentivo das atividades discentes. A retroalimentação ou feedback (ALLAL; MOTTIER, 2007; CRAHAY, 2007) interativa, retroativa ou proativa do desempenho do aluno é essencial para que ele possa modificar ou ajustar seu comportamento com a finalidade de alcançar o resultado positivo de seu empenho. Uma revisão dessas reações docentes - positiva, negativa, desconexa, irônica, as quais são meramente formais -, tem importante ressonância no aprendizado. Compete, assim, ao docente ponderá-las em seus comentários para que seja alcançado o objetivo formador de sua avaliação.

\section{Conclusão}

A avaliação formativa voltada para garantir o direito de aprender pode parecer uma tarefa inviável diante das condições objetivas de muitas escolas ou da precariedade da formação docente em um campo especializado da avaliação ou, ainda, diante da diversidade do público escolar em um mundo afetado por mudanças globais, sociais, culturais e tecnológicas, reconhecendo, com Snyders (1984), que não é fácil amar nossas crianças.

Pesquisadores aplicados enfatizam que a avaliação, competência essencial do professor e central na prática pedagógica, deve ser constitutiva da planificação, centrada no modo como os alunos aprendem e nas várias formas de sucesso escolar, pois ajuda o aluno a melhorar sua competência, reforça a motivação, desenvolve a capacidade dos alunos se auxiliarem e permite a

Práxis Educativa, Ponta Grossa, p. 561-576, v. 11, n. 3, set./dez. 2016 Disponível em: <http://www.revistas2.uepg.br/index.php/praxiseducativa> 
melhor compreensão dos objetivos pedagógicos e dos critérios de avaliação (BLACK; WILIAM, 1998, 2001).

Algumas instâncias educacionais, interessadas na superação da tirania da avaliação (DEL REY, 2013) ou dos pesadelos da avaliação (ANTIBI, 2007) meramente somativa, e, também, alguns sistemas de educação, assombrados com os prejuízos da reprovação (CNESCO; IFÉ, 2015), buscam inovações na área para alcançar padrões mais adequados de avaliar os resultados da aprendizagem.

A Conferência Internacional sobre aprender no século XXI (OCDE; CERI, 2008) indica seis princípios fundamentais para a avaliação formativa a partir de pesquisas e estudos de caso: a instauração de uma cultura de classe que encoraje a interação e a utilização de instrumentos de avaliação; a definição dos objetivos de aprendizagem e acompanhamento dos progressos individuais dos alunos para esses objetivos; a utilização de métodos de ensino variados para responder às necessidades diversificadas dos alunos; recorrer a métodos também diversificados para avaliar os resultados dos alunos; dar feedbacks das performances dos alunos e adaptar o ensino para responder às necessidades identificadas; e, finalmente, a implicação ativa dos alunos no processo de aprendizagem (OCDE; CERI, 2008). A Conferência completa com sugestões em domínios em que as pesquisas poderiam contribuir: ampliar as investigações sobre métodos formativos apoiadas no acúmulo de experiências educativas internacionais; privilegiar estudos que auxiliem alunos em dificuldades; desenvolver métodos de avaliação mais frutuosos para os diferentes grupos socioeconômicos ou demográficos; avaliar o impacto das avaliações formativas nas emoções, nas motivações e nas auto percepções dos alunos; expandir o repertório de métodos de ensino e aprendizagem dos professores para atender necessidades específicas de alunos com maiores dificuldades; e, se a avaliação formativa confronta-se com muitos obstáculos, as pesquisas poderiam difundir o sucesso do valor formativo das avaliações e aprofundar conhecimentos sobre as melhores estratégias formativas.

Caberia uma questão: nenhuma sanção é admissível às transgressões dos alunos na escola? Para ser educativa, argumenta Prairat (2009), qualquer sanção deve ter finalidade ética, social e política: só há sentido ético na sanção se o aluno estiver consciente e for responsável pelo que fez, a fim de que a sanção lhe restitua a consciência de sua ação e o torne responsável pelos seus atos; a sanção deve ter uma finalidade social: uma parada que vise restabelecer o vínculo social, desfeito com a transgressão; e política: visar o restabelecimento da qualidade das normas de convívio social, quebrada com a transgressão, e não mera estratégia para recuperar a autoridade e poder do professor.

Se a avaliação formativa não é panaceia, nem deve ser um modismo efêmero. As políticas públicas não podem desconhecer as críticas, as pesquisas e os avanços científicos nessa prática educativa. As consequências de avaliações seletivas, marginalizando os alunos com dificuldades escolares e reprovando os que mais carecem da educação escolar, não são fatalidades e devem ser assumidas pelas políticas públicas, pois não significam, somente, um prejuízo particular para o aluno; são, também, onerosas para o erário público. Se não há estimativa estatística desse custo no Brasil, a França, que se estima zelosa da educação pública gratuita, avalia que representa um custo, humano e orçamentário, relevante (CNESCO, 2014). O direito de aprender das novas gerações impõe o dever de propor políticas de avaliação que as motivem para o aprendizado que a escola oferece. Se os processos avaliativos podem comprometer o desejo de aprender e, no limite, excluir muitos alunos que não encontraram apoio em suas dificuldades ou não foram incentivados em suas descobertas, as políticas públicas de avaliação precisam incentivar a cultura da avaliação formativa como meio de garantir a avaliação justa dos esforços de todos os que têm o direito de aprender na educação escolar. Há um amplo consenso sobre a necessidade de 
melhorar as condições de aprendizagem e sucesso dos alunos. O desafio é transformar a avaliação em uma política que desperte e motive o interesse dos alunos pela educação escolar.

\section{Referências}

ALLAL, L.; MORTIER, L. L. L'évaluation formative de l'apprentissage: revue de publications em langue française. In: OCDE. L'évaluation formative: pour um meilleur apprentissage des les classes secondaires. OCDE: Paris, 2007. p. 265-290.

ANTIBI, A. La constante macabre ou comment a-t-on découragé des génerations d'élèves. Math'Adore, 2003.

ANTIBI, A. Les notes: la fin du cauchemar. Paris: Nathan, 2007.

BARREIRA, C.; BOAVIDA, J.; ARAÚJO, N. Avaliação formativa: Novas formas de ensinar e aprender. Revista Portuguesa de Pedagogia, Coimbra, v. 40, n. 3, p. 95-133, 2006.

BLACK, P.; WILIAM, D. Assessment and classroom learning. Assessment in education, v. 5, n. 1, p. 7-71, 1998. DOI: 10.1080/0969595980050102

BLACK, P.; WILIAM, D. Inside the block box: raising standards through classroom assessment. London: NFER Nelson, 2001. Disponível em: < http://weaeducation.typepad.co.uk/files/blackbox-1.pdf>. Acesso em: 18 fev. 2015.

BLOOM, B. S.; HASTING, J. T.; MADAUS, G. F. Manual de avaliação formativa e somativa da aprendizagem escolar. São Paulo: Pioneira, 1983.

BRASIL. Ministério da Educação. Secretaria da Educação Básica. Proposta da Secretaria da Educação Básica com contribuições da Secretaria de Educação Continuada, alfabetização, diversidade e inclusão. Para a construção do documento da educação base nacional comum curricular: orientações quanto à forma e a abrangência. Brasília: MEC; SEB, jun. 2015.

BURGNARD, P-P. La note, invention des temps modernes. Formation et pratiques des enseignement en question, Fribourg, n. 1, p. 89-95, 2004.

BUTERA, F.; BUCHS, C.; DARNON, C. (Orgs.). L'évaluation, une menace. Paris: Presses Universitaires de France, 2011.

CARDINET, J. Histoire de 1'évaluation scolaire: des origines à nos jours. Neuchâtel: INRD, Recherche, 1991.

CASTINCAUD, F.; ZAKHARTCHOUK, J-M. L'évaluation plus juste et plus efficace: commet faire?. Collection Repères pour agir, Canope CRDP d'Amiens - Crap - Cahiers pédagogiques, juin 2014.

CEDES. Carta de Campinas. Seminário de avaliação e políticas públicas educacionais, 2011. Disponível em: <www.cedes.unicamp.br/CartadeCampinas.pdf>. Acesso em: 12 jun. 2015.

CHIZZOTTI, A. A pesquisa educacional e o movimento 'pesquisas científicas baseadas em evidência'. Práxis Educativa, Ponta Grossa, v. 10, n. 2, p. 329-342, jul./dez. 2015. DOI: 10.5212/PraxEduc.v.10i2.0003 
CHIZZOT'TI, A.; PONCE, B. J. Avaliação da produção docente no ensino superior: possibilidades e limites. Revista e-Curriculum, São Paulo, v. 5, n. 2, jul. 2010.

CLAPARÈDE, É. L'école sur mesure. Lausanne-Genève: Payot, 1920.

CNESCO. Conseil National de l'Évaluation du Système Scolaire. Évaluation des élèves dans la classe. 2014. Disponível em: <http://www.cnesco.fr/fr/evaluation-des-eleves-dans-la-classe/>. Acesso em: 2 fev. 2015.

CNESCO; IFÉ. Conseil National de l'Évaluation du Système Scolaire (CNESCO); Institut Français de l'Éducation (IFÉ Ens-Lyon). Conférence de Consensus « Lutter Contre les Difficultés Scolaires: Le Redoublement et ses Alternatives? Recommandations du jury, 27 et 28 jan. 2015. Disponível em: <cnesco.communication@education.gouv.fr>. Acesso em: 12 jun. 2015.

CRAHAY, M. Feedback de l'enseignement et apprentisage des élèves: revue critique de la littérature de recherche. In: ALLAL, L.; MOTTIER, L. L. Regulations des apprentissages em situation scolaire et en formation. Bruxelles: De Boeck, 2007. p. 45-70.

DEL REY, A., La tyranie de l'évaluation. Paris: La Découvrte, 2013.

FEYFANT, A. Les effets de l'éducation familiale sur la réussite scolaire. Dossier d'actualité Veille et analyses, n. 63, jun. 2011.

FOUCAULT, M. Vigiar e Punir: nascimento da prisão. 36. ed. Petrópolis, RJ: Vozes, 2009.

HADJI, C. Faut-il avoir peur de l'évaluation? Bruxelles: De Boeck, 2012.

HEIM, A.; TRICOT, A.; STEINMETZ, C. Faut-il encore redoubler? Paris: CANOPE, 2015. Disponível em: <https://www.reseau-canope.fr/notice/faut-il-encore-redoubler.html>. Acesso em: 20 fev. 2015.

LHÉRETÉ, H. Dossier Éduquer au XXI siècle. Sciences Humaines, Auxerre, 2014.

MAULINI, O. Qui a eu cette idée folle un jour d'inventer (les notes) à l'école? Petite histoire de l'évaluation chiffrée à l'usage de celles et ceux qui désirent s'en passer (et des autres). Réflexion conduite en marge de débats organisés par AGATHA: Abolir la note à l'école: quels effets? Des notes à l'école, pour quoi faire ? Genève: Faculté de Psychologie et des Sciences de l'Éducation, 1996.

MAULINI, O. Resserer ou justifier les classements? L'évaluation scolaire entre deux injonctions. Diversité, n. 169, p. 133-137, 2012.

MERLE, P. L'éleve humilié. L'école, un space de non-droit? Paris: Presses Universitaíres de France, 2005.

MERLE, P. Les notes. Secrets de fabrication. Paris: Presses Universitaíres de France, 2007.

MERLE, P. La ségregation scolaire. Paris: La Decouverte; Repères, 2012.

MERLE, P. Faut-il en finir avec les notes? La vie des idées, 2 déc. 2014. Disponível em: <http://www.laviedesidees.fr/Faut-il-en-finir-avec-les-notes.htlm>. Acesso em: 20 fev. 2015.

NATIONAL RESEARCH COUNCIL. Scientific research in education. Committee on Scientific Principles for Education Research. R. J. Shavelson \& L. Towne. (Eds.). Washington, 
DC: National Academic Press, 2002. Disponível em: <http://www.nap.edu/catalog/10236/scientific-research-in-education>. Acesso em: 18 fev. 2015.

NATIONAL RESEARCH COUNCIL. Advancing scientific research in education. Committee on scientific principles for education research. L. Towne, L. Wise \& T. M. Winters. (Eds.). Washington, DC: National Academic Press, 2005. Disponível em: $<$ http://www.nap.edu/catalog/11112/advancing-scientific-research-in-education>. Acesso em: 18 fev. 2015.

NUSCHE, D. et al. (Orgs.). OECD. Reviews of evaluation and assessment in education. Synergies for better learning: an international perspective on evaluation and assessment. Paris: OCDE, 2013.

OCDE; CERI. Organisation de Cooperation et de Developpment Economiques. Centre pour la Recherche Et L'innovation Dans L'enseignement (Ocde/Ceri). Évaluation de l'apprentissage. L'évaluation formative. Conférence Internationale OCDE/CERI "Apprendre au XXIe. siècle: recherche, innovation et politiques". Paris: OCDE, 2008.

PRAIRAT, E. Eduquer et punir. Généalogie du discours psychologique. Nancy: Presses Universitaires de Nancy, 1994.

PRAIRAT, E. La sanction en éducation. Paris: Presses Universitaires de France, 2009.

REY, O; FEYFANT, A. Évaluer pour (mieux) faire apprendre. Dossier d'actualité Veille et Analyses de 1'IFÈ. n. 94, set. 2014, Lyon: ENS de Lyon. Disponível em: <http://ife.enslyon.fr/vst/DA/detailsDossier.php?parent $=$ accueil\&dossier $=76 \& l a n g=f r>$. Acesso em: 20 fev. 2015.

RYAN, K. E.; COUSINS. J. B. The Sage International Handbook of Educational Evaluation. Thousands Oaks, CA: Sage Publications, 2009.

SANTO AGOSTINHO. Confissões. Petrópolis, RJ: Vozes, 2000.

SAUL, A. M. Avaliação emancipatória: desafios à teoria e à prática de avaliação e reformulação de currículo. 3. ed. São Paulo: Cortez, 1995.

SCALLON, G. L'évaluation des apprentissages dans une approche para compétences. Bruxelles: De Boeck, 2007.

SCHNEIDER, B.; KEESLER, V.; MORLOCK, L. Les influences familiales sur l'apprentissage et la socialisation des enfants. In: OECD. Comment apprend-on? La recherche au service de la pratique. Paris: OCDE. 2010. DOI: 10.1787/9789264086944-fr

SNYDERS, G. Não é fácil amar os nossos filhos. Lisboa: Dom Quixote, 1984.

SUCHAUT, B. La loterie des notes au bac. Un réexamen de l'arbitraire de la notation des élèves. Les documents de travail de l'IREDU, n. 3, p. 1-18, 2008. Disponível em: <https://halshs.archives-ouvertes.fr/halshs-00260958v2/document>. Acesso em: 15 fev. 2015.

TEDDIE, C.; REYNOLDS, D. (Orgs.). The International handbook of school effectiveness research. London, New York: Falmer Press, 2000. 
UNESCO. ISCED. International Standard Classification of Education (ISCED). Paris: UNESCO, 2011.

UNESCO. UNICEF. Education pour tous (EPT). Rapport mondial de suivi: jeunes et compétences - éducation au travail. Paris: UNESCO; UNICEF, 2012.

UNESCO. UNICEF. Institute for Statistics. Fixing the broken promise of education for all: findings from the global initiative on out-of-school children. Montreal, Quebec: UNESCO, Institute for statistics (UIS), 2015. Disponível em: $<$ http://www.uis.unesco.org/Education/Documents/oosci-global-exsum-en.pdf $>$. Acesso: 20 jun. 2015.

Recebido em 24/11/2015

Versão corrigida recebida em 08/04/2016

Aceito em 11/04/2016 